\title{
Color-coded Imaging Enables Fluorescence-guided Surgery to Resect the Tumor Along with the Tumor Microenvironment in a Syngeneic Mouse Model of EL-4 Lymphoma
}

\author{
KOSUKE HASEGAWA ${ }^{1}$, ATSUSHI SUETSUGU ${ }^{1,2,3}$, MIKI NAKAMURA ${ }^{1}$, TAKURO MATSUMOTO ${ }^{1}$, \\ TAKAHIRO KUNISADA ${ }^{1}$, MASAHITO SHIMIZU ${ }^{1}$, SHIGETOYO SAJI ${ }^{1}$, \\ HISATAKA MORIWAKI $^{1}$, MICHAEL BOUVET ${ }^{3}$ and ROBERT M. HOFFMAN ${ }^{2,3}$ \\ ${ }^{1}$ Gifu University Graduate School of Medicine, Gifu, Japan; \\ ${ }^{2}$ AntiCancer, Inc., San Diego, CA, U.S.A.; \\ ${ }^{3}$ Department of Surgery, University of California San Diego, San Diego, CA, U.S.A.
}

\begin{abstract}
Background/Aim: Fluorescence-guided surgery (FGS) of cancer is an emerging technology. We have previously shown the importance of resecting both the tumor and the tumor microenvironment (TME) for curative FGS. We also previously developed a syngeneic model using the mouse lymphoma cell line EL-4, expressing red fluorescent protein (EL-4-RFP), growing in green fluorescent protein (GFP) transgenic mice, which we have used in the present report to develop FGS of the tumor microenvironment. Materials and Methods: EL-4-RFP lymphoma cells were injected subcutaneously in C57/BL6 GFP transgenic mice. EL-4-RFP cells subsequently formed tumors by 35 days after cell transplantation. Using the portable hand-held Dino-Lite digital imaging system, subcutaneous tumors were resected by FGS. Resected tumor tissues were visualized with the Olympus FV1000 confocal microscope. Results: Using the Dino-Lite, subcutaneous tumors and the tumor microenvironment were clearly visualized and resected. In the resected tumor, host stromal cells, including adipocyte-like cells and blood vessels with lymphocytes, were observed by confocal microscopy in addition to cancer cells by color-coded confocal imaging. The cancer cells and stromal cells in the TME were deeply
\end{abstract}

This article is freely accessible online.

Correspondence to: Robert M. Hoffman, $\mathrm{PhD}$, AntiCancer, Inc., 7917 Ostrow Street, San Diego, CA 92111, U.S.A. Tel: +1 8586542555, Fax: +1 8582684175, e-mail: all@anticancer.com and Atsushi Suetsugu MD, PhD, Department of Gastroenterology, Gifu University Graduate School of Medicine, 1-1 Yanagido, Gifu 5011194, Japan. Tel: +81 582306308, Fax: +81 582306310, e-mail: asue@gifu-u.ac.jp

Key Words: Tumor microenvironment, TME, transgenic GFP mouse, RFP, fluorescence-guided surgery, color-coded, imaging, Dino-Lite. intermingled in a highly-complex pattern. Conclusion: Colorcoded FGS is an effective method to completely resect cancer cells along with the stromal cells in the TME which interact in a highly-complex pattern. Microscopically, cancer cells invade the TME and vice versa. To prevent tumor recurrence, it is necessary to resect the TME along with the tumor.

Fluorescence-guided surgery (FGS) of cancer is an emerging technology. Our laboratory has pioneered mouse models using fluorescent proteins, as well as fluorescent antibodies, to label tumors for FGS (1-11).

To achieve complete tumor resection, it is necessary to understand the relationship between cancer cells and stromal cells in the tumor microenvironment (TME) (9). We previously reported imaging of the TME during tumor progression and metastasis by color-coding cancer and stromal cells (12-27).

We have subsequently used genetic reporters to color code cancer and stroma cells in a patient-derived orthotopic xenograft (PDOX) model. Cancer cells were labeled with a telomerasedependent green fluorescent protein (GFP)-containing adenovirus (OBP-401) in a pancreatic cancer PDOX. The PDOX was labeled in the stroma by red fluorescent protein (RFP) during growth in transgenic mice that express RFP (9).

In the present report, we developed a color-coded syngeneic model for FGS using a mouse lymphoma cell line (EL-4), expressing RFP, and transgenic C57/B6 mice ubiquitously expressing GFP under the control of the chicken $\beta$-actin promoter and cytomegalovirus enhancer. Using the portable, hand-held Dino-Lite fluorescence microscope, the EL-4-RFP tumor in the GFP mouse was color-coded imaged in order to visualize the tumor and TME and resected by FGS. Confocal microscopy of the resected tumor demonstrated that both tumor and the TME were completely resected by color-coded FGS. In the resected RFP-expressing tumor, various types of GFPexpressing stromal cells were observed intermingling with the cancer cells in the TME. 


\section{Materials and Methods}

Cell line and culture. EL-4, a mouse lymphoma cell line, was previously established from a lymphoma induced in a C57BL mouse by 9,10-dimethyl-1,2-benzanthracene (24). The cells were maintained in RPMI 1640 medium supplemented with $10 \%$ heatinactivated fetal bovine serum (FBS), 1\% penicillin and streptomycin (Gibco-BRL, Grand Island, NY, USA). The cells were cultured at $37^{\circ} \mathrm{C}$ in a $5 \% \mathrm{CO}_{2}$ incubator.

RFP fluorescent protein transduction of lymphoma cells. EL-4 lymphoma cells were labeled with RFP as previously reported (24) using a retrovirus-based vector containing RFP.

GFP transgenic mice. Transgenic C57BL/6-GFP mice (25) were obtained from the Research Institute for Microbial Diseases (Osaka University, Osaka, Japan). The C57BL/6-GFP mice expressed the Aequorea victoria GFP under the control of the chicken $\beta$-actin promoter and cytomegalovirus enhancer.

EL-4-RFP malignant lymphoma subcutaneous tumor in C57/BL6GFP mice. Six-week-old transgenic GFP mice, described above, were used as the host for EL-4-RFP lymphoma cells. RFP EL-4 lymphoma cells were first harvested by trypsinization and washed three times with cold serum-free medium and then resuspended with serum-free RPMI 1640 medium. RFP EL-4 lymphoma cells were injected subcutaneously in C57BL/6-GFP transgenic mice.

Tumor imaging. The FV1000 confocal microscope (Olympus Corp, Tokyo, Japan), was used for ex vivo imaging (28). The BX53 microscope (Olympus) was used for histological sections. Resection of the subcutaneous tumor was performed using the portable imaging system equipped with a Dino-Lite digital fluorescence microscope (AM4113T-GFBW and AM4113TYFGW Dino-Lite Premier; AnMo Electronics Corp., Hsinchu, Taiwan) (6).

Study approval. All experiments were conducted in accordance with the institutional guidelines of Gifu University and approved by the Animal Research Committee and the Committee on Living Modified Organisms of Gifu University (approval number 26-37).

\section{Results and Discussion}

Subcutaneous lymphoma growth. The EL-4-RFP lymphoma cells were injected subcutaneously in C57/BL6-GFP transgenic mice. The cells subsequently formed subcutaneous tumors by 35 days after cell injection (Figure 1).

Color-coded fluorescence-guided surgery (FGS) with a hand-held portable imaging system. FGS of the subcutaneous tumor was performed using the Dino-Lite portable imaging system. In the RFP-fluorescence mode (Figure 1A), subcutaneous tumors and tumor margins were clearly visualized compared with bright-field. In the GFPfluorescence mode, host GFP-labeled stromal cells were visualized at the tumor margin (Figure 1B).
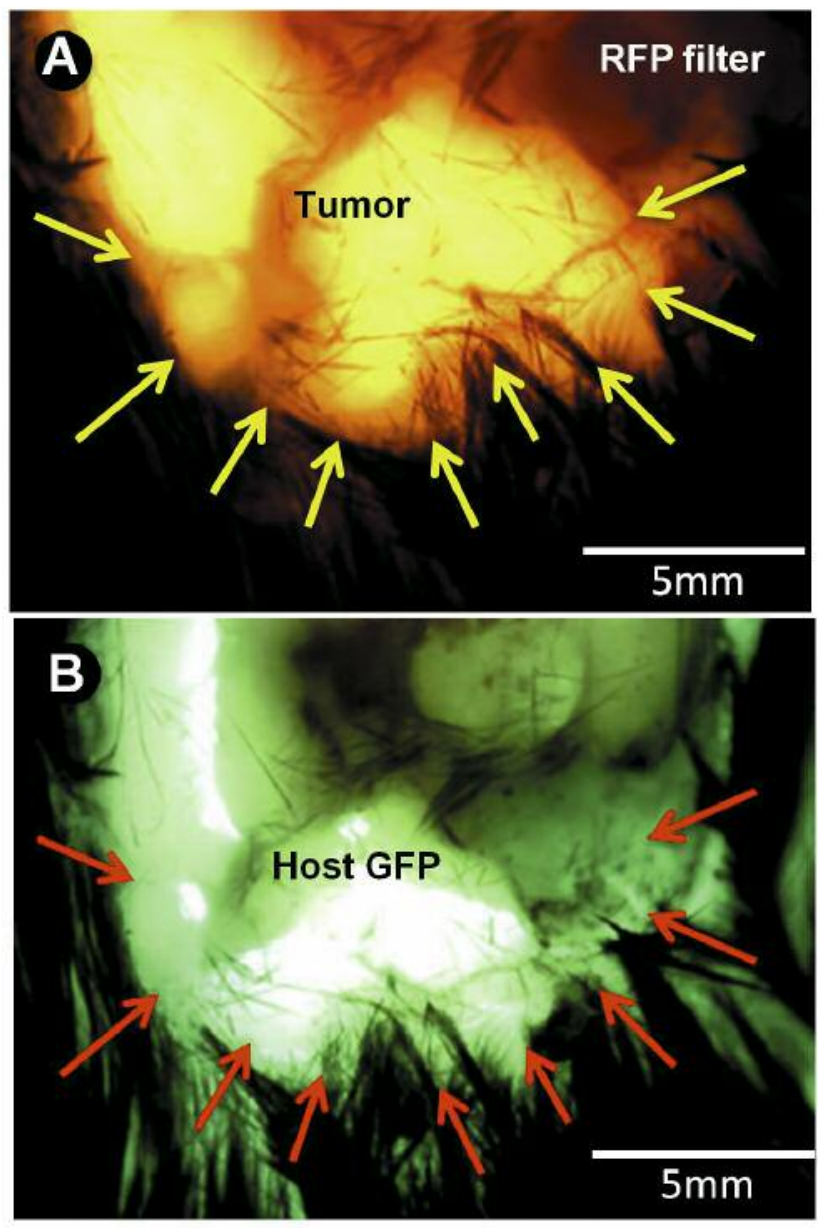

Figure 1. Pre-operative images of the EL-4-RFP lymphoma tumor, 35 days after subcutaneous injection of cancer cells. A: RFP fluorescence image of the pre-operative subcutaneous tumor. RFP-labeled cancer (yellow arrows show the tumor margin). B: GFP fluorescence image of the subcutaneous tumor. Stromal cells are visualized in the tumor tissue (red arrows). All images were captured with the Dino-Lite digital portable imaging system at a magnification of $20 \times($ bar=5 $\mathrm{mm})$.

Ex vivo color-coded imaging of cancer-cell and host stromalcell interaction. The tumor surface contained both RFP cancer cells and GFP stromal cells (Figure 2A). Highresolution, high-magnification color-coded confocal imaging demonstrated that host GFP stromal cells were diffusely distributed inside the tumor in a highly complex pattern (Figure 2B). Tumor blood vessels containing GFP-expressing lymphocytes and adipocyte-like cells within the tumor tissue were imaged (Figure 2C-D). The fluorescence images were confirmed histopathologically in formalin-fixed, paraffinembedded specimens (Figure 3A-F).

Using color-coded imaging, the tumor margin and interactions of host stromal cells with cancer cells were more clearly visualized. We demonstrated that host stromal cells 
(A)
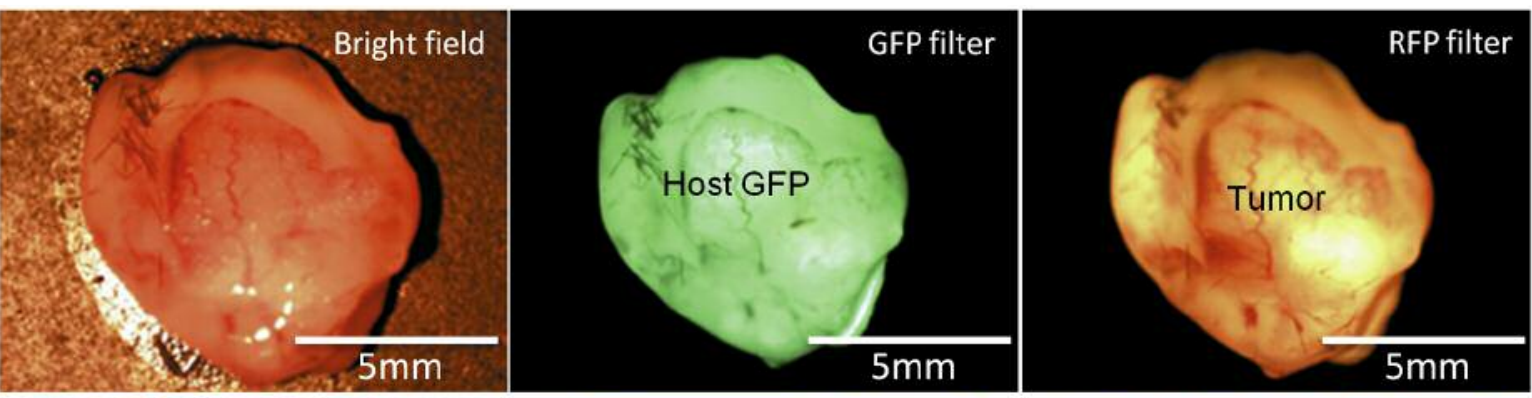

(B)
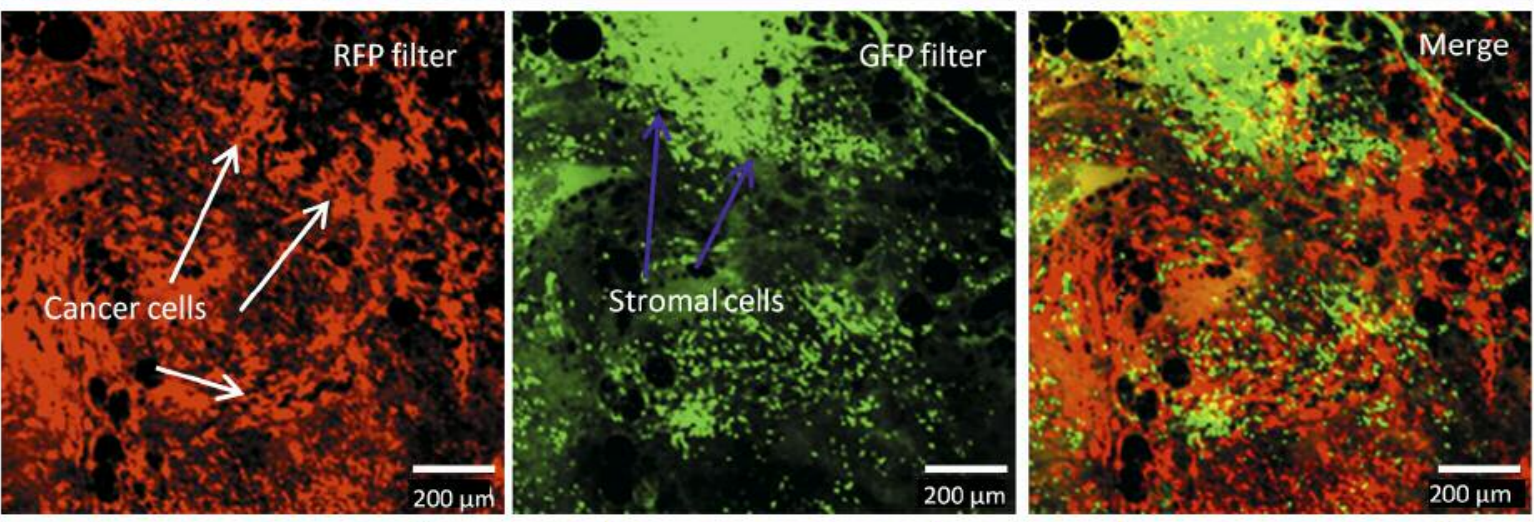

(C)
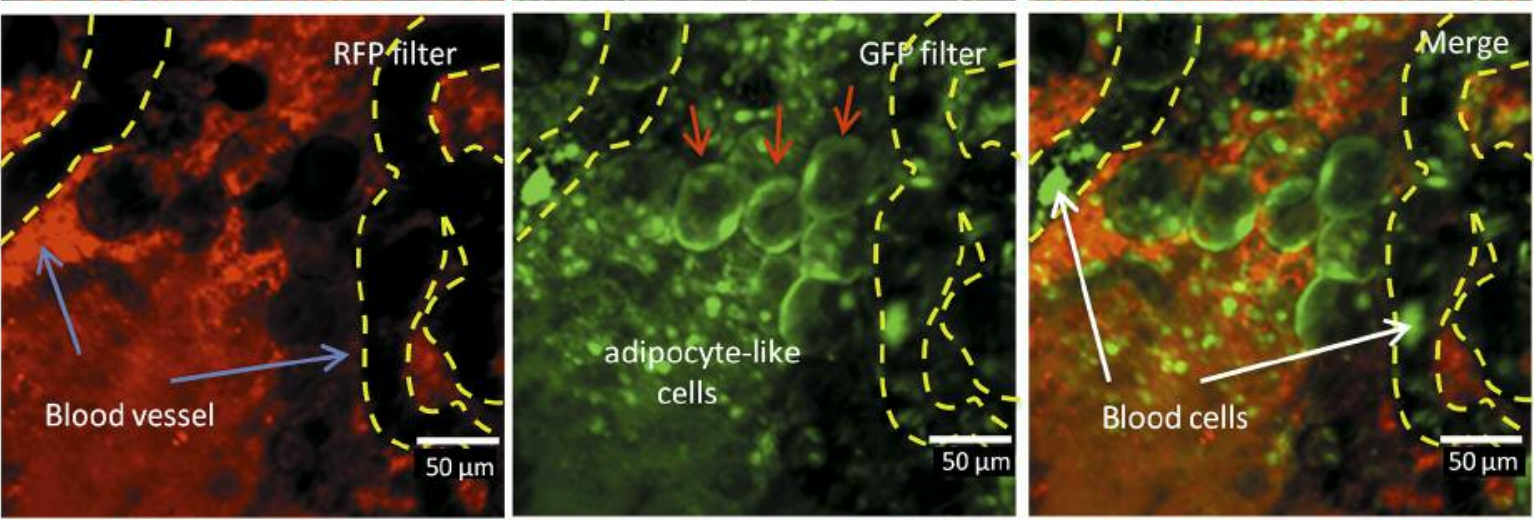

(D)
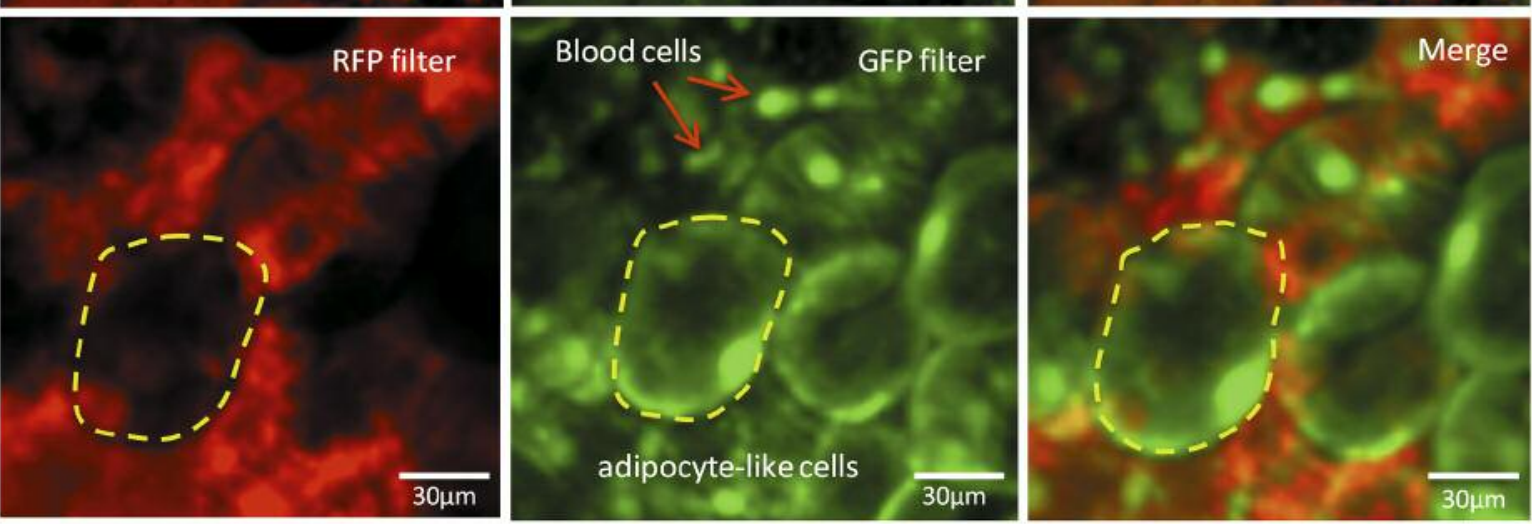

Figure 2. Color-coded imaging of a resected tumor and its microenvironment (TME). A: Bright-field and fluorescence images of a resected specimen, including tumor and TME (bar=5 mm). Images were captured with a Dino-Lite portable, digital microscope. B: Low-magnification imaging of the tumor tissue and tumor microenvironment (TME). White arrows indicate EL-4-RFP lymphoma cells. Blue arrows indicate host stromal cells. Right panel shows merged image. Host stromal cells are observed within the tumor $($ bar $=200 \mu \mathrm{m})$. C: High-magnification images of the tumor tissue and TME. Blue arrows indicate the tumor blood vessels surrounded by yellow dotted lines. GFP-expressing lymphocytes can be visualized within the blood vessels. In the GFP fluorescence image (middle panel), red arrows indicate adipocyte-like cells. White arrows indicate the blood cells in the tumor blood vessel (bar $=50 \mu m)$. D: High-magnification images of the adipocyte-like cells. Red arrows indicate blood cells. B-D: Images were captured with an FV1000 confocal microscope. 

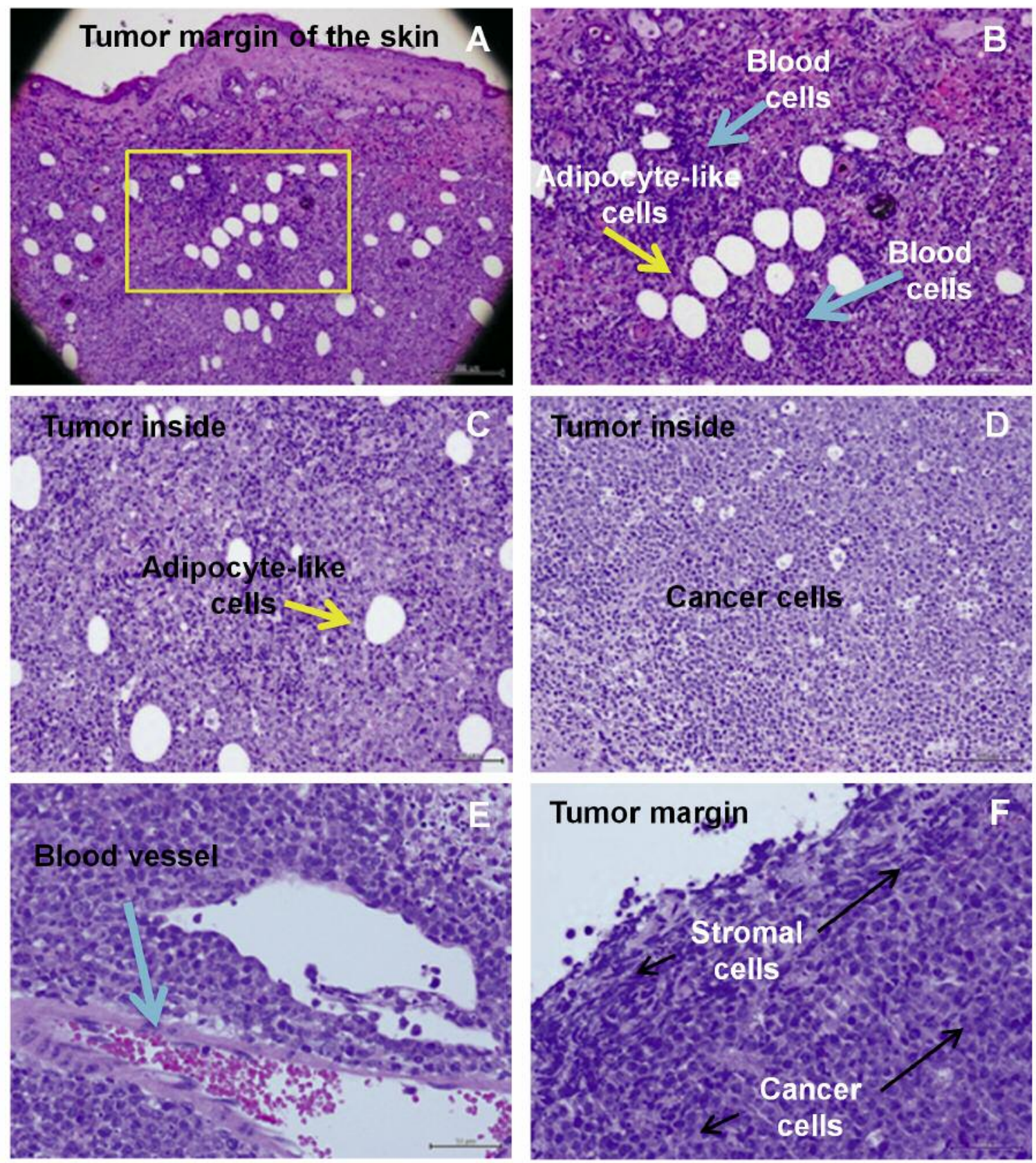

Figure 3. Histopathological analysis of the resected tumor samples with H\&E staining. A: Subcutaneous tissue and tumor margin on the skin side. B: High-magnification image of the yellow box in A. Yellow arrow indicates adipocyte-like cells. Blue arrow indicates blood cells. C-F: Highmagnification images of the tumor and TME. All images were captured with a BX53 microscope.

were deeply intermingled within the tumor and that cancer cells also invaded the TME indicating the highly complex interactions of cancer and stromal cells. The cancer cells within the TME are possibly the main cause of local recurrence after surgery.

In a previous study, color-coded FGS, which distinguished cancer and stroma, significantly prevented local recurrence, which bright-light surgery or single-color FGS could not (9). The present report further emphasizes the importance of resecting the TME in FGS. FGS is now emerging in the clinic (29-31) and should become the standard paradigm in the near future

\section{Conflicts of Interest}

None of the Authors has any conflict of interest in regard to this study. 


\section{Dedication}

This paper is dedicated to the memory of A.R. Moossa, MD and Sun Lee, MD.

\section{References}

1 McElroy M, Kaushal S, Luiken G, Moossa AR, Hoffman RM and Bouvet M: Imaging of primary and metastatic pancreatic cancer using a fluorophore-conjugated anti-CA19-9 antibody for surgical navigation. World J Surgery 32: 1057-1066, 2008

2 Kaushal S, McElroy MK, Luiken GA, Talamini MA, Moossa AR, Hoffman RM and Bouvet M: Fluorophore-conjugated antiCEA antibody for the intraoperative imaging of pancreatic and colorectal cancer. J Gastrointest Surg 12: 1938-1950, 2008.

3 Kishimoto H, Zhao M, Hayashi K, Urata Y, Tanaka N, Fujiwara $\mathrm{T}$, Penman $\mathrm{S}$ and Hoffman RM: In vivo internal tumor illumination by telomerase-dependent adenoviral GFP for precise surgical navigation. Proc Natl Acad Sci USA 106: 14514-14517, 2009.

4 Bouvet M and Hoffman RM: Glowing tumors make for better detection and resection. Sci Transl Med 3: 110sf10, 2011.

5 Metildi CA, Kaushal S, Hardamon CR, Snyder CS, Pu M, Messer KS, Talamini MA, Hoffman RM and Bouvet $M$ : Fluorescence-guided surgery allows for more complete resection of pancreatic cancer, resulting in longer disease-free survival compared with standard surgery in orthotopic mouse models. J Am Coll Surg 215: 126-136, 2012.

6 Hiroshima Y, Maawy A, Sato S, Murakami T, Uehara F, Miwa S, Yano S, Momiyama M, Chishima T, Tanaka K, Bouvet M, Endo I and Hoffman RM: Hand-held high-resolution fluorescence imaging system for fluorescence-guided surgery of patient and cell-line pancreatic tumors growing orthotopically in nude mice. J Surg Res 187: 510-517, 2014.

7 Hiroshima Y, Maawy A, Zhang Y, Sato S, Murakami T, Yamamoto M, Uehara F, Miwa S, Yano S, Momiyama M, Chishima T, Tanaka K, Bouvet M, Endo I and Hoffman RM: Fluorescence-guided surgery in combination with UVC irradiation cures metastatic human pancreatic cancer in orthotopic mouse models. PLoS One 9: e99977, 2014.

8 Hiroshima Y, Maawy A, Zhang Y, Murakami T, Momiyama M, Mori R, Matsuyama R, Katz MH, Fleming JB, Chishima T, Tanaka K, Ichikawa Y, Endo I, Hoffman RM and Bouvet M: Metastatic recurrence in a pancreatic cancer patient derived orthotopic xenograft (PDOX) nude mouse model is inhibited by neoadjuvant chemotherapy in combination with fluorescence-guided surgery with an anti-CA 19-9-conjugated fluorophore. PLoS One 9: e114310, 2014.

9 Yano S, Hiroshima Y, Maawy A, Kishimoto H, Suetsugu A, Miwa S, Toneri M, Yamamoto M, Katz MHG, Fleming JB, Urata $\mathrm{Y}$, Tazawa H, Kagawa S, Bouvet M, Fujiwara T and Hoffman RM: Color-coding cancer and stromal cells with genetic reporters in a patient-derived orthotopic xenograft (PDOX) model of pancreatic cancer enhances fluorescenceguided surgery. Cancer Gene Therapy 22: 344-350, 2015.

10 Murakami T, Hiroshima Y, Zhang Y, Bouvet M, Chishima T, Tanaka K, Endo I and Hoffman RM: Improved disease-free survival and overall survival after fluoresence-guided surgery of liver metastasis in an orthotopic nude mouse model. J Surg Oncol 112: 119-124, 2015.
11 Yano S, Takehara K, Miwa S, Kishimoto H, Hiroshima Y, Murakami T, Urata Y, Kagawa S, Bouvet M, Fujiwara T and Hoffman RM: Improved resection and outcome of coloncancer liver metastasis with fluorescence-guided surgery using in situ GFP labeling with a telomerase-dependent adenovirus in an orthotopic mouse model. PLoS One 11: e0148760, 2016.

12 Hoffman RM and Yang M: Color-coded fluorescent imaging of tumor-host interactions. Nature Protoc 1: 928-935, 2006.

13 Hoffman RM: The multiple uses of fluorescent proteins to visualize cancer in vivo. Nat Rev Cancer 5: 796-806, 2005.

14 Yang M, Li L, Jiang P, Moossa AR, Penman S and Hoffman RM: Dual-color fluorescence imaging distinguishes tumor cells from induced host angiogenic vessels and stromal cells. Proc Natl Acad Sci USA 100: 14259-14262, 2003.

15 Yang M, Reynoso J, Jiang P, Li L, Moossa AR and Hoffman RM: Transgenic nude mouse with ubiquitous green fluorescent protein expression as a host for human tumors. Cancer Research 64: 8651-8656, 2004.

16 Yang M, Jiang P and Hoffman RM: Whole-body subcellular multicolor imaging of tumor-host interaction and drug response in real time. Cancer Res 67: 5195-5200, 2007.

17 Yang M, Reynoso J, Bouvet M and Hoffman RM: A transgenic red fluorescent protein-expressing nude mouse for color-coded imaging of the tumor microenvironment. J Cell Biochem 106: 279-284, 2009.

18 Suetsugu A, Osawa Y, Nagaki M, Saji S, Moriwaki H, Bouvet $M$ and Hoffman RM: Imaging the recruitment of cancerassociated fibroblasts by liver metastatic colon cancer. J Cell Biochem 112: 949-953, 2011.

19 Suetsugu A, Hassanein MK, Reynoso J, Osawa Y, Nagaki M, Moriwaki H, Saji S, Bouvet M and Hoffman RM: The cyan fluorescent protein nude mouse as a host for multicolor-coded imaging models of primary and metastatic tumor microenvironments. Anticancer Res 32: 31-38, 2012.

20 Suetsugu A, Katz M, Fleming J, Moriwaki H, Bouvet M, Saji S and Hoffman RM: Multi-color palette of fluorescent proteins for imaging the tumor microenvironment of orthotopic tumorgraft mouse models of clinical pancreatic cancer specimens. J Cell Biochem 113: 2290-2295, 2012.

21 Suetsugu A, Snyder CS, Moriwaki H, Saji S, Bouvet M and Hoffman RM: Imaging the interaction of pancreatic cancer and stellate cells in the tumor microenvironment during metastasis. Anticancer Res 35: 2545-2551, 2015.

$22 \mathrm{Ke} \mathrm{CC}$, Liu RS, Suetsugu A, Kimura H, Ho JH, Lee OK and Hoffman RM: In vivo fluorescence imaging reveals the promotion of mammary tumorigenesis by mesenchymal stromal cells. PLOS ONE 8: e69658, 2013.

23 Suetsugu A, Katz M, Fleming J, Truty M, Thomas R, Saji S, Moriwaki H, Bouvet $M$ and Hoffman RM: Non-invasive fluorescent-protein imaging of orthotopic pancreatic-cancerpatient tumorgraft progression in nude mice. Anticancer Res 32: 3063-3068, 2012.

24 Matsumoto T, Suetsugu A, Shibata Y, Nakamura N, Aoki H, Kunisada T, Tsurumi H, Shimizu M and Hoffman RM: A colorcoded imageable syngeneic mouse model of stromal-cell recruitment by metastatic lymphoma. Anticancer Res 35: 4647$4654,2015$.

25 Okabe M, Ikawa M, Kominami K, Nakanishi T and Nishimune Y: 'Green mice' as a source of ubiquitous green cells. FEBS Lett 407: 313-319, 1997. 
26 Bouvet M, Tsuji K, Yang M, Jiang P, Moossa AR and Hoffman RM: In vivo color-coded imaging of the interaction of colon cancer cells and splenocytes in the formation of liver metastases. Cancer Res 66: 11293-11297, 2006.

27 Yang M, Reynoso J, Bouvet M and Hoffman RM: A transgenic red fluorescent protein-expressing nude mouse for color-coded imaging of the tumor microenvironment. J Cell Biochem 106: 279-284, 2009.

28 Uchugonova A, Duong J, Zhang N, König K and Hoffman RM: The bulge area is the origin of nestin-expressing pluripotent stem cells of the hair follicle. J Cell Biochem 112: 2046-2050, 2011.

29 Urano Y, Sakabe M, Kosaka N, Ogawa M, Mitsunaga M, Asanuma D, Kamiya M, Young MR, Nagano T, Choyke PL and Kobayashi H: Rapid cancer detection by topically spraying a Yglutamyltranspeptidase-activated, fluorescent probe. Sci Transl Med 3: 110ra119, 2011.
30 van Dam GM, Themelis G, Crane LM, Harlaar NJ, Pleijhuis RG, Kelder W, Sarantopoulos A, de Jong JS, Arts HJ, van der Zee AG, Bart J, Low PS and Ntziachristos V: Intraoperative tumorspecific fluorescence imaging in ovarian cancer by folate receptor- $\alpha$ targeting: First in-human results. Nat Med 17: 13151319, 2011.

31 Stummer W, Pilchmeier U, Meinel T, Wiestler OD, Zanella F, Reulen HJ; ALA-Glioma Study Group: Fluorescence-guided surgery with 5-aminolevulinic acid for resection of malignant glioma: A randomised controlled multicentre phase III trial. Lancet Oncol 7: 392-401, 2006.
Received June 28, 2016

Revised July 14, 2016

Accepted July 15, 2016 